Marquette University

e-Publications@Marquette

$1-1-2014$

\title{
Did Schelling Misunderstand Fichte's Transcendental Method?
}

Michael Vater

Marquette University, michael.vater@marquette.edu

Accepted version. "Did Schelling Misunderstand Fichte's Transcendental Method?" in Fichte and Transcendental Philosophy. Eds. Tom Rockmore and Daniel Breazeale. London: Palgrave Macmillan 2014: 257-272. DOI. @ 2017 Springer International Publishing AG. Used with permission. 


\title{
Did Schelling Misunderstand Fichte’s Transcendental Method?
}

\author{
Michael Vater
}

Marquette University

The Fichte-Schelling Correspondence interweaves intriguing personal stories and philosophical combat. One of the sadder personal stories involves Schelling getting wind of Fichte’s remark to Friedrich Schlegel that he did not understand transcendental method. The letters document several clumsy attempts by Fichte to minimize the criticism, ${ }^{1}$ only to have it surface again in a letter Fichte wrote to a former student, Jean Baptiste Schad, who showed the letter to Schelling. ${ }^{2}$ In it, Fichte claimed that Schelling understood Wissenschaftslehre no better than Friedrich Nicolai, whom Fichte had publicly excoriated for critiquing as ‘I-philosophy’ a superficial assemblage of random quotes from mixed sources. - For months before this end of the cover-up Fichte and Schelling were engaged in a struggle over whether there were one or many Wissenschaftslehres, or if one, it had the empty universality of logic, or if many, it could be a gerrymandered entity that encompassed Fichte’s initial exposition and the newly opened territory of Schelling's Naturphilosophie. The personal situation between our two philosophers was delicate: Fichte and Schelling, who considered themselves friends and philosophical allies, had more or less promised to keep their differences private and talk through their difficulties. Each had the habit of furnishing the other with recent publications, though neither put much effort into reading them. The letters they exchanged, while not casually composed, served not so much to solidify a common position as to project personal visions of each individual's own completed system. They have the intense quality of the discussions about-to-be-former partners have before calling in the lawyers. Indeed, the Schad letter ended the relationship. 
My concern, however, is not tabloid history, but the truth of Fichte's assertion that there was something called 'transcendental method,' that he understood it, and that Schelling-- as evidenced by the appearance of the System of Transcendental Idealism and subsequent writings-did not. We can point to three phases in each thinker's ideas of philosophical system and method in the years 1794 to 1802/03. An exact side by side comparison of positions is not possible, since each evolved following its own logic and in somewhat willful ignorance of the other's: Schelling retained the memory of the first two parts of the 1794 Foundations as his referent for 'Wissenschaftslehre' and seems not to have noticed the 1797-1798 Attempt at a New Presentation. Having confronted Schelling's early dalliance with realism in that work's Second Introduction, ${ }^{3}$ Fichte ignored Schelling's first attempts at fashioning a philosophy of nature, and was dismayed to discover a deduction of nature as the theoretical part of Schelling's 1800 'System of Idealism'. While it will take a detailed exploration to uncover the truth of the claim Fichte first made to Schlegel, there is an interesting, though accidental, commonality in Fichte's and Schelling's writings of 1801: each writer turns to Spinoza as the model for philosophical method and locates philosophical certainty (or Evidenz) in something like a fundamental axiom or postulate. It is beyond the scope of this paper to explore this in detail, ${ }^{4}$ but one can imagine that after the shock of Kant's public disavowal of Wissenschaftslehre, both Fichte and Schelling return to the First Critique's Doctrine of Method and take seriously what Kant has to say about science, certainty, and construction in the mathematical sciences and in philosophy. ${ }^{5}$

Our first task will be to recount the phases of Fichte's reflections on philosophical method; we shall focus on three texts, two known by Schelling and a third which, though 
unpublished in his lifetime, was reflected in a work known by him, the 1801 Crystal Clear Report.

The 1794 Foundations of the Entire Wissenschaftslehre employs the language of "abstraction" and the philosopher's free "reflection" to motivate the acceptance of the Grundsätze which are laid out at the beginning of the theoretical philosophy. Consciousness is founded in an absolute Tatsache that is presumed by all states of empirical consciousness, but not found among them; the philosopher thinks his way to this primal ground through abstracting reflection (GA I/2: 254). In the ensuing train of reflection, the philosopher comes upon the primitive form of the law of identity, the I = I, which expresses what will later be called intellectual intuition: "One cannot think anything without additionally thinking one’s I as selfconscious; one can never abstract from one's self-consciousness." Only by assuming a genetic account of this primitive Tatsache can a system of idealism be achieved, and it will be expressed approximately as: “The I originally and simply posits its own being” (GA I/2: 259). A similar line of reflection establishes the other two fundamental principles, whose postulation is grounded in an examination of the more empirically accessible acts of consciousness examined in the work's third part, the account of intelligence as praxis, founded on striving, feeling, and drive.

The background for Fichte's 1794 reflections on method is Spinoza's concept of determination or determinate negation and Kant's the famous question about the justification of synthetic a priori judgments. The first two fundamental principles, the I's positing of itself and its positing of a not-I opposed to itself, lead to the third: the I posits itself as divided, or a divisible I posits itself in opposition to a divisible not-I. If one abstracts from specific content, we have here the principle of divisibility, the ground of divisibility and conjunction for all further determination in reflection (GA I/2: 272). Divisibility is thus the ground of both "antithetic" (or 
analytic) procedure—seeking opposite factors in things that have been equated—and synthetic procedure --discovering in opposites the elements whereby they are alike or can be equated. No analysis, then, without synthesis, and no synthesis without analysis. And, pace Kant, no purely analytic or pure synthetic judgments, for in Fichte's initial system there is an absolute selfpositing of the I if and only if there is a positing of a divisible I opposite a divisible not-I (GA I/2: 274). The Wissenschaftslehre's 'synthetic method' pushes forward rather than coming to a stand-still only because antithesis and synthesis both depend on thesis; the double-sided third principle does not cancel itself out because the logic or activity of the first pushes the deduction forward. “The system's form is grounded in the highest synthesis, that there be a system in the first place is grounded in the absolute thesis" (GA I/2: 276). The upshot is that the system's deductions only appear to go forward; the highest or last synthesis is present from the first, and progress in philosophical reflection consists only in the application of more refined names or categories to the ever-present knot of I and not-I.

For the sake of tracking phases of Fichte's development, we can call the method that Fichte pursues in 1794 postulation.

For the second moment of Fichte's reflections on philosophical methodology, we turn to the 1797-1798 Attempt at a New Presentation of the Wissenschaftslehre, with its two Introductions that address the confrontation of dogmatism and idealism and its fragmentary first chapter. While Schelling could not have known directly of the new experimental turn that marked Fichte’s 1796/99 nova methodo lectures, he probably was aware that he had provoked Fichte's acid remarks in the two Introductions on moral character and one's choice of philosophical orientation with his comments in the 1795 Letters on Dogmatism and Criticism which seemed to tolerate a realism alongside idealism. ${ }^{6}$ That this old "error"' and its correction 
enter into the epistolary quarrels of 1801 over whether Schelling ever "penetrated the Wissenschaftslehre" suggests that Schelling did not take Fichte’s concern seriously when it was published in $1797 .^{7}$

If one can describe the 1794 Grundlage as historical-and-reflective in the way it established its Grundsätze and analytic-and-synthetic in its exposition of the details of the knot of determinacy and freedom that is the I's reality, the New Attempt is experiential or experimental in its foundation and even more explicitly synthetic-and-analytic in its exposition. The First Introduction lays out the key elements: The finite rational being is or has nothing but its experience, and it is equally a thinking and an observing of thinking. The philosopher possesses the power of abstraction or the dissection of what is observed into elements, one of which can be postulated as primary, and the others derived as conditions of the first (GA I/4:188). Transcendental idealism takes the bare experience of having a presentation as its postulate, and by a process of reasoning from what is conditioned to what conditions it arrives at a complete system of necessary presentations (GA I/4: 205).

The Second Introduction offers a more complicated view of the same process, giving the name 'intellectual intuition' to the first experiential-abstractive moment. This first postulation occurs in response to a command: think yourself. What happens in response to the command is the experience denominated 'agility'. The I is revealed as self-reverting act: “All that pertains to the I is the act of turning back upon itself" (GA I/4: 213). Having an I and being an I depends upon doing an I. This performative intuition is always accompanied by two things--a sensory intuition of some sort and a goal or prompt: Think yourself! Think of the wall! (GA I/4: 217). And while this experiment seems banal, when the context is expanded to that of life as a whole and the prompt in question is the ethical command, one can see that intellectual intuition is the 
bond between the sensible and the intellectual worlds, the one place where I can catch of glimpse of myself as full actor (GA I/4: 219-221).

The Attempt's fragmentary first chapter adds little to this account that is new except to underline that what is precisely intuitive in the performance of the I is the experience of transiting from repose to acting-- the edge between indeterminacy and determinacy, between possibility of response and reaction to the command or prompt. The state of latency, or justbeing-an-I, is really the concept of an I. One really is an I only when one is agile and catches the intellectual intuition in the act of doing the I. The I when performed is always accompanied by the concept of the I, the concept of something stable and enduring named the I (GA I/4: 279-81). One must discard the static image of judgment as the combination of discrete psychological items, intuitions in themselves and concepts in themselves, and view thinking operationally as an incessant interweaving of active and latent (conceptual) phases—of the I's own self-enactment. Little wonder that Kant himself could not recognize his own philosophy in the Wissenschaftslehre's reconstruction of it!

We can label Fichte’s 1797 methodology intellectual intuition, with the caution that the underlying view of the nature of the I has not changed: self-postulation, agility, self-reversion, intellectual intuition all name the same wellspring of activity that is self-conscious life.

Around the turn of the century, Fichte contemplated a new version of Wissenschaftslehre that deepened its experiential character but looked to geometrical method, as analyzed by Kant and as practiced by Spinoza, to shore up the connection between the intuitive beginning of the philosophical system and its deductive elaboration. The fragmentary 1800 New Version of the Wissenschaftslehre was abandoned after three months' work, but some of its line of thought 
came to Schelling's attention in the Announcement of the project in an early 1801 issue of Fichte's Philosophical Journal and in the Crystal Clear Report to the Public. ${ }^{8}$

The Announcement directly confronts Fichte's somewhat embarrassed position after the 1799 public denunciations of Wissenschaftslehre by Kant and Jacobi. To make Wissenschaftslehre comprehensible, Fichte must rescue terms like 'intuition' and 'intellectual intuition' from Kant’s static usage ${ }^{9}$--and 'concept’ too, most likely. Philosophy cannot be, as Kant argued, rational cognition through concepts, in contrast to mathematics, which is rational cognition through intuitions. ${ }^{10}$ Indeed if there is cognition via intuitions in mathematics and geometry, there must be a cognition of this cognition, a mathesis of mathesis. Philosophy can be independent of concepts, including a static and ready-made concept of philosophy, if and only if it is "the cognition of reason itself by means of itself." Only on the condition of being a living self-cognition is philosophy entitled to undertake the task of critiquing reason—extending, criticizing, justifying, and ultimately correcting cognition. ${ }^{11}$

Wissenschaftslehre is mathematics, claims Fichte, and because it is rational cognition in intuition it has the self-evidence and universal validity of the postulates and theorems of mathematics. It shares three marks with the mathematical sciences: immediate self-evidence, complete determinacy (no matter what signs or symbols are chosen to convey its content), and irrefutability. ${ }^{12}$ The terms Fichte uses in this discussion (intuition or intellectual intuition) carry the same performative sense they did in 1797 . He does not employ Kant's term construction here as he does in the New Version itself, but the term aptly designates a method which is transparently certain because it is active or self-directing, and self-correcting because it is selfaware. $^{13}$ 
There is little in the way of historical reflection in the New Version, but under the subheading 'Historical Narrative', Fichte looks back at earlier formulas that summarize the core of his thought: Wissenschaftslehre discovers that thinking apprehends itself as self-reverting thinking or it experiences its own activity as agility. ${ }^{14}$ These are both formulations of Kant's great discovery, in fact "his only lucid thought," that immediate self-consciousness is the necessary condition of every other state of consciousness. ${ }^{15}$ Fichte agonizes over whether this proposition is a postulate or a theorem. It is not a postulate in the sense of an arbitrary or provisional assumption, though it will carry self-evidence with it once it has been proved. Nor is it a theorem in the sense of something proved by means of concepts. But since it is proved in intuition (or construction), it is more akin to the latter than the former. ${ }^{16}$ The real hallmarks of this intuitive procedure are that: (1) it is free of received meanings, even the conventional reference of terms, (2) a free production of all the facts of consciousness, (3) it resides in the free thinking of the reader/author, and (4) it is genuinely free, not connected with the exigencies of life. ${ }^{17}$

In terms of content, beyond the exploration of what could be an initial postulate or theorem, Fichte's real effort in this manuscript is to intuitively develop what is meant by agility. As in the 1797/98 Attempt, agility is the experienced response to a command from without, a wrenching away from repose—something that is novel, situational, experienced, and of finite duration. Mental life is intellect's commutation between pervasive passive states (concept) and freely initiated activity (intuition). ${ }^{18}$

The most striking feature of this manuscript is Fichte's self-questioning, his struggle to put the actual experience of freedom (in Kant's sense of starting something new) into words. What the 'first postulate' or the first free response to command shows is not even a subject, but a 
pure reflex of consciousness that only appears to be a reflex from the point of view of something posited later and governed by it—a formal rather than a material I, one that is at once particular and universal, eternal, invariable, permanent, and ingredient in all states of consciousness. ${ }^{19}$ The situation of being between action and repose--of being able to further determine one's determinability-- is the I's ambiguous situation of being activity against a background of already determined being or repose: being mere faculty. The contrast is understood only to the extent it is experienced, and the activity is said to "create itself out of nothing." 20

Fichte employs the dialogue form in the Crystal Clear Report, which lends a sort of elegance to the "Do I really understand this?" questioning interjected into the New Version. He again focuses on the parallel between the geometry and Wissenschaftslehre. Both sciences start from a point of self-evidence, for the geometer perhaps an angle formed by two lines, for the philosopher, the unity of consciousness given in all consciousness. In both cases, the startingpoint is highly abstract, but universally valid. The science proceeds in reason, and so each reader in fact constructs the point of evidence and everything that follows from it for herself (GA I/7: 229-33). Science describes a series of intuitions which are necessarily interconnected, so it is not a matter of describing actual figures or actual minds, or of finding the right words to communicate actual states of affairs; it is a matter of rational construction freely undertaken, a work of abstraction (GA I/7: 237-38).

If we bring these scattered remarks from 1800-1801 together we get an image of Wissenscahftslehre as 'scientific' philosophy, rooted in the evident certainly of the I's own activity, accessible to non-scientists because they too can perform the experiment of freely thinking $X$, whose propositions or theorem are demonstrated because they are a progressive 
series of intuitions. The characteristic methodology of earlier versions need not be rejected; instead they are brought forward and unified as construction in intellectual intuition.

\section{II}

We turn now to Schelling. We can also discern three phases in his thinking on transcendental method from 1799-1802/03. This is a more compressed time frame than in Fichte's case, but since for a good part of the time he is in intense discussions with Fichte, it is not surprising that he finally arrives at something like Fichte's understanding. What is problematic, however, is whether the words "construction in intellectual intuition" mean roughly the same thing when applied to transcendental philosophy and when applied to nature.

In the 1800 System of Transcendental Idealism, the method Schelling uses to ground and integrate the five epochs of consciousness ${ }^{21}$ into one system is quite complicated. In preliminary reflections on methodology, one can see a 'synthetic' method that parallels Fichte's overall procedure in the Foundations of the Entire Wissenschaftslehre: the final synthesis is present from the beginning for the philosopher who untangles the overall synthesis into a series of discrete analyses and partial synthetic reconstructions, and so produces a pragmatic history of consciousness.

There are no less than four sets of methodological reflections at the beginning of the work. (1.) An initial set of remarks (§ 1) consider philosophical cognition as 'bare knowing’. Since philosophy is a knowing and knowing is an identification of opposites-- knower and known, or the subjective and the objective-- systematic philosophy must have two major parts, philosophy of nature and transcendental philosophy. In the first, objectivity predominates and the observing philosopher recounts the emergence of intelligence within nature; in the second, 
subjectivity predominates and the philosopher recounts the solidification of individual will into social, legal, political and historical totalities (HkA I/ 9, 1: 29-32). ${ }^{22}$-Fichte is highly critical of this beginning, for it sunders transcendental idealism into two equal but opposite accounts, and in fact prizes nature or preconscious activity over self-consciousness. It considers intelligence only in objectified form, whether that be nature, law or the object of theology. In doing so, it loses the warrant that intellectual intuition gives to idealism, the self-evident postulate that all states of consciousness bring with them and are founded on self-consciousness. ${ }^{23}$

(2.) A corollary set of remarks (§ 2) consider philosophy more specifically as 'transcendental knowing,' which is said to be an artifice (Kunst) put in place subsequent to a skeptical dissociation of consciousness and its supposedly external objects. While in the lifeworld all thinking, knowing and action are characterized by a disappearance of the subjective into the objective, transcendental knowing reverses the direction and displays all mental activities as the self-objectification of the primordially subjective (HkA I/9, 1: 35).

(3.) A section on the organ or instrument of transcendental philosophy (§ 4) underscores the fictional or imaginative aspect of the transcendental philosopher's procedure: if one is confined to the subjective or one's own activity, but there is no direct access to this activity, selfintuition must take the detoured route of production and reflection-intuition, with the former prior but hidden, and the latter always subsequent and after the fact. This imbalance persists throughout the whole series of deductions, until the perpetually hidden subjective element of productive intuition becomes its own object in aesthetic intuition. Only in the crafting of the work of art do production and intuition come to identity (HkA I/9,1: 40-42). -Schelling speaks the language of aesthetics in this section, but Fichte correctly perceives his interest is theological; poet, sculptor, and philosopher have essentially the same calling, to display productive intuition 
(or imagination) as its product. What is Athena but objectified intelligence, Phidias’ own creative intelligence ${ }^{24}$

These three aspects of transcendental methodology are introduced in System of Transcendental Idealism's Introduction. (4.) The actual system begins with a statement of its system-principle, the I = I, which expresses the nature of self-consciousness. The transcendental philosopher postulates an absolute principle within consciousness, and the complete derivation of all its consequences establishes the system along with its principle in a coherentist, nonfoundational manner. The system as a whole vindicates the assumption that subjectivity is prior in accounting for the being of the objective, or it shows that the apparent imbalance inherent in transcendentalism’s prioritizing the subjective-productive aspect of knowing actually demonstrates the identity of knower and known (HkA I:9, 1: 43-49). This cashes out to the view, quite consistent with Fichte’s original version of Wissenschaftslehre, that I and not-I are joined in one synthetic act. How this one act which can be spelled out only as a series of discrete acts is explained by Schelling on the model that the 'Deduction of Presentation' offered in that work: a self-positing that is at once the positing of activity and its limitation (HkA I:9, 1: 6878). -Fichte seems to find this a defective procedure which substitutes a sheer opposition of different activities for the self-limitation of activity that is at the heart of Wissenschaftslehre's account of objectivity. ${ }^{25}$

It is difficult to discern whether these extensive and varied comments amount to one coherent position on transcendental method. The ‘postulation' involved in the presentation of the Grundsätze of Fichte’s Grundlage seemed to be foundational; later developments such as introduction of 'intellectual intuition' and the stress on the almost geometrical evidence of the experienced coincidence of self-consciousness and all discrete states of consciousness reinforce 
this impression. Schelling's procedure seems more hypothetical-deductive: the transcendental assumption of the priority of subjectivity and its active expression is cashed out in coherentist fashion alone, with such completeness and closure as can be achieved by substituting aesthetic intuition for the ever-missing intellectual intuition.

A second moment in Schelling's evolution on transcendental method can be seen in his General Deduction of the Dynamic Process, which appeared shortly before the System of Transcendental Idealism was published. Here Schelling speaks of the sole task of natural science as the "construction of matter," a task that can be accomplished only generally, not for each discrete appearance in nature. Since organic nature is but a higher level or potency of the inorganic, the construction of matter is at once the most basic and the most general task of a philosophy of nature. ${ }^{26}$ The task involves the heuristic assumption that there is an ideal subject of nature in which is found a primordial opposition of forces, one of which is called 'expansive' and signifies only a pure production which can never appear, the other called 'retarding' or 'attractive'; the latter is responsible for the introduction of duplicity, hence of the real production that results from the absolute opposition of these forces, or from their expression in opposite directions, denominated 'centrifugal' and 'centripetal'. All the specific levels of the dynamic process on the inorganic level—magnetism, electricity, and chemical interaction—can be viewed as but different functions of the universal endeavor to reduce the opposite factors to identity once more and reinstate original identity in place of the duplicity that underlies natural appearances. ${ }^{27}$ Just as all the multiplicity of nature's inorganic products can be viewed as mixtures of these three basic processes, so all the phenomena of organic nature stem from mixtures of their organic correlates—sensibility, irritability and reproduction. These parallels were established in the System of Transcendental Idealism as phases in the history of self-consciousness, so that 
Naturphilosophie serves not only as a redaction of the discovery of the natural sciences but as a "physicalistic explanation of idealism."28

Schelling concludes this essay with some important methodological remarks. Humans are not pure spirits, and we can approach the truth of our own nature only by putting aside subjective views and learning to view ourselves purely theoretically, purely objectively. Nature serves as a transcendental reminder of the state in which we were one with nature, and so Naturphilosophie serves a function analogous to that of sensible experience in Plato's doctrine of the anamnesis of ideas. It is somewhat arbitrary whether we explain nature from ourselves or ourselves from nature, but the true path for one who prizes scientific knowledge (Wissen) before all else is the one that nature herself has trod. At the same time, our only access to such a comprehensive view of nature is through the sort of pragmatic history of consciousness that the System of Transcendental Idealism expounds. The idealistic viewpoint is the key to nature's secrets, not the atomistic and experimental procedure of Newton's followers. ${ }^{29}$

Had Fichte read this essay, as Schelling repeatedly asked him to in the course of the Correspondence, it is not clear if it would have brought him around to the view that Schelling was expanding the parameters of Wissenschaftslehre with his addition of philosophy of nature to transcendental philosophy, or whether he was altering it beyond recognition. ${ }^{30}$ While the overall method of this presentation of nature remains the hypothetical-deductive model of the transcendental system, Schelling pursues the sort of geometrical modeling of natural forces throughout the piece that Eschenmayer had suggested to him, for it is seemingly natural to represent opposed forces or tendencies as differences of direction on a straight line. The constructions of the dimensions of space, of the factors in gravity, and of magnetic and electrical 
polarity all lend themselves to geometrical treatment. Therefore, we can label this phases of Schelling's reflections on transcendental method construction.

We can find a third phase of Schelling's reflections on method in the 1801 Presentation of My System and the 1802 Further Presentations from the System of Philosophy. The Presentation itself contains little in the way of explicit reflection on philosophical method. The system begins with a merely verbal definition of reason as the absolute indifference of the subjective and the objective, and asserts, by way of explanation, that reflection must find it way to this standpoint by something analogous to a geometrical construction which locates the midpoint of indifference between the extremes of the subjective and the objective. 'The subjective' and 'the objective' are non-referring terms and are so abstract, here at the start, that their only meaning is their mutual contrast. From the human point of view, the only way to 'absolute indifference' is through surrender of subjectivity, the abandonment of the personal or I-centered stance. Since the personal or subjective point of view refers to the having of appearances, the initial move of identity philosophy can only be an indirect suggestion that there is a transsubjective stance, that of reason, that all being must be conceived therein, not in the opposition of subject and appearances found in empirical consciousness, and that only the bare identity of the law of identity $(\mathrm{A}=\mathrm{A})$ governs the procedures of reason $(H \mathrm{kA} \quad \mathrm{I} / 10: 116-119)$. Only the nonessential difference between $\mathrm{A}$ as subject and $\mathrm{A}$ as predicate in that law provides a way forward for the deduction.

Surrender of subjectivity or abandonment of the particularity of situated consciousness is linked to the themes of the evidence of mathematical sciences, intellectual intuition, and philosophical construction in a series of essays Schelling published in 1802. A first essay offers a general treatment of the possibility of absolute cognition, which is analogous to but not 
identical with constructive mode of mathematics and especially geometry, but quite different from that offered by contemporary skepticism or Kantian criticism or Wissenschaftslehre. The madness of explaining things not as they are in their totality, but only as teased out into dualistic relations of cause and effect is what most distances one from the indifference of intuition and thought, and it is the mathematical sciences, with their prizing not of explanation but of demonstration, that have provided the first general example of method free of this erroneous tendency (SSW IV: 344-45). Although they have been able to furnish an example of a formally absolute cognition, mathematics and geometry have not been able to illuminate the difference between philosophy and their domains. The first step toward philosophy is to immediately intuit the unity of the real and the ideal in itself, not as subordinated to the finite power in the first, and to the infinite in the latter (SSW IV: 347-48). While Fichte is praised as the first to bring to light the idea of absolute philosophy, he is happy to stick with the perspective of an I opposed to a not-I, and thus is limited by the same causal principle Kant brought to the fore as the sole tool for explaining appearances (SSW IV: 353-54).

In a second essay, Schelling offers an ontological proof, arguing from the idea of a formally absolute cognition to its reality. In the absolute there is an identity of form and substance. If one has the idea of absolute cognition, one has the absolute itself; this is what is meant by intellectual intuition. It is what enables the philosopher to display the archetype or eternal ideas in his constructions, just as the geometer is able to display them in outer intuition. What characterizes an idea, as opposed to a concept that clearly retains connection to a reality external to the concept, is an immediate union of universality and particularity. ${ }^{31} \mathrm{~A}$ fourth essay considers the depiction that an idea receives in absolute philosophy, where both universal and particular factors are reflected in each other in something akin to an artistic creation. The 
product is a 'construction', what produces it is 'intellectual intuition', and when the process is carried through to systematic totality it is called 'demonstration'. ${ }^{32}$ The idea constructed in intellectual intuition, the plant the botanist studies or the animal the zoologist comes to know, is the universe in particular form. When it needs to be displayed in discursive form, this same idea is the connecting thread or the principle of demonstration. ${ }^{33}$

Demonstration will serve as a label for this third phase of methodological reflection. What remains is to explicitly contrast the views of Fichte and Schelling, especially in their most developed phases.

III

Let us look back. With Fichte, we had the phases of postulation, intellectual intuition, and finally construction in intellectual intuition. With Schelling, we had those of hypotheticaldeductive process, construction, and demonstration, the last of which is virtually the same as Fichte's construction in intellectual intuition. The words are the same, but when claims of evidence are asserted, especially in comparison with geometric method, it makes all the difference what sort of object these methods treat. In moving from the Foundations of 1794 to the works of 1800-1801 Fichte worked from more abstract to more concrete treatments, from a postulated pure I to something the reader can experience-or more precisely, to something whose analogue Fichte's reader can experience when she responds to the command: think yourself! What is experienced is precisely 'agility': something new happens, initiated by the subject, and it is the transition from rest to motion or "being torn out of repose."

As Schelling's ideas of transcendental methodology evolve, the object they attach to become more abstract; the philosopher's claimed 'intellectual intuition' is different from or beyond the reach of empirical intuition, or the self-intuition of the empirical subject. Both works 
of 1800, the System of Transcendental Idealism and the General Deduction of Dynamic Process, involve the insertion of an ideal or fictive subject into the subject-matter. And the element of imagination is echoed in the use of Ineinsbildung, or the imaginative interweaving of the universal and the particular, in the essays of 1802.

Both our philosophers agree that imaginative projection—or fiction, to put it bluntly—is at the heart of the enterprise of building a philosophical system. In November of 1800, Fichte writes:

The reality of nature is different again. The latter appears in transcendental philosophy as something thoroughly found.... Science only makes nature into its object through a subtle abstraction and obviously has to posit nature as something absolute (precisely because it abstracts from the intelligence), and lets nature construct itself by means of a fiction, just as transcendental philosophy lets consciousness construct itself by means of an equivalent fiction. ${ }^{34}$

While he will not agree that nature is something purely found, Schelling agrees that its construction (or reconstruction) in philosophy has the nature of fiction:

But if you were to ... then say that the philosophy which I call purely theoretical is precisely the science you speak of in your letter, namely, one which would make nature alone its object through a free abstraction, and then permit it to construct itself through a (justifiable) fiction, this is entirely and absolutely my view.... ${ }^{35}$

The whole difference between our two philosophers lies in the proximity or remoteness of the transcendental subject from the empirical self that is abstracted from. Schelling is aware that he has a problem when he speaks in 1802 of the difference between the apparent vacuity of the "night absolute" and the fullness of the "day absolute" and contrasts the two in theological terms 
as the still and immutable eternal Father and the Son who steps forth in his own shape as living wisdom. ${ }^{36}$ In a footnote that summarized the first set of 1802 essays that is prefaced to the second set, Schelling speaks of the absolute's substance essence (the "night absolute") in this way:

... [T]he absolute is determined as that which is intrinsically neither thought nor being, but which, for that very reason, is absolute. Since reason is challenged to conceive the absolute neither as thought nor as being but still to think it, a contradiction arises for reflection, since for it everything is either a case of being or one of being. But intellectual intuition enters even into the contradiction and produces the absolute. In this breakthrough lies the luminous point where the absolute is positively intuited. (Intellectual intuition is therefore merely negative within reflection.) Through this positive intuition, philosophical construction as such is first made possible, or exhibition in the absolute which is the same thing. ${ }^{37}$

What is lacking is an ample treatment of reason and reflection, or of 'negative' and 'positive' intellectual intuition. That task awaits Hegel's pen. 
${ }^{1}$ See Fichte to Schelling, 3 October 1800 (PRFS, p. 32). Fichte mentions the incident again in Fichte to Schelling, 21/22 October 1800 (ibid., p. 37). Schelling complains of further suggestions made in the Allgemein Deutsche Bibliotek and Nicolai's Lebens that he did not understand Fichte's philosophy and that only auditors of his lectures possibly could, in Schelling to Fichte, 3 October 1801, (ibid., p 65). Cp. Friedrich Nicolais Leben und sonderbare Meinungen (GA I/7, pp. 430-31).

${ }^{2}$ See Schelling to Fichte, 25 January 1802 in PRFS, pp. 74-75. On Fichte’s letter to Schad, see note 250, p. 242.

${ }^{3}$ IWL p. 38n.

${ }^{4}$ See David W. Wood, Mathesis of the Mind: a Study of Fichte's Wissenschaftslehre and Geometry (Amsterdam/New York: Rodopi, 2012).

${ }^{5}$ Compare J. G. Fichte, Announcement and F.W.J. Schelling, Further Presentations from the System of Philosophy in PRFS, pp. 87-88 and pp. 206-207.

${ }^{6}$ In the First Introduction, Fichte seems to echo Schelling's remark that one’s choice of system will be a function of one's character: “The kind of philosophy one chooses thus depends on the kind of person one is” (GA I/4: 195). But near the beginning of the Second Introduction Fichte appends a note that suggests there cannot be two equally valid sorts of philosophy, but only one where the philosopher, in his own name, explains the very objectivity that life and science seem to conjoin to presentations from his own self, his own free speculation (GA I/4: 210n-211n).

${ }^{7}$ See Fichte to Schelling, 31 May - August 7/8, 1801 and Schelling to Fichte, 3 October, 1801 in PRFS, pp. 54 and 63. 
${ }^{8}$ Both Fichte and Schelling turned to Kant's Doctrine of Method in the Critique of Pure Reason in the autumn of 1800 and tried to incorporate Kant's analysis of mathematics and especially geometry as “construction in non-empirical intuition” into their philosophical method. Fichte’s Announcement is dated 4 November, 1800. On 7 September of that year, Schelling sent an issue of his Zeitschrift für speculative Physik to his printer, Gabler, that promised a complete system as a reply to Eschenmayer’s objections about the supposed independence of Naturphilosophie. So it seems that Schelling was at work on his Presentation of My System at roughly the same time Fichte was working on the New Version. Both works speak of transcendental philosophy as construction in intellectual intuition.

${ }^{9}$ Announcement in PRFS, pp. 88-89.

${ }^{10}$ Kant, Discipline of Pure Reason, in the 'Doctrine of Method', $K r V$, A712/B740 - A 716/B744. The same passage introduces the idea that the intuitive side of mathematics is construction in pure or a priori intuition.

${ }^{11}$ Announcement, op. cit., pp. 87-88.

12 Ibid., pp. 89-90.

${ }^{13}$ See New Version of the Wissenschaftslehre, in PRFS, pp. 94, 96 (GA II/5: 332, 336).

14 Ibid., p. 94 (GA II/5: 332).

15 Ibid., p. 104 (GA II/5: 346).

16 Ibid., p. 96 (GA II/5: 335).

17 Ibid., p. 95 (GA II/5: 333-34).

${ }^{18}$ Ibid., pp. 108-113 (GA II/5: 352-360).

${ }^{19}$ Ibid., pp. 104-105; see also p. 116 (GA II/5: 347, 363).

${ }^{20}$ Ibid., pp. 111, 113 (GA II/5: 356-57). 
${ }^{21}$ The five epochs - nature, the social domain of human existence (will, ethics, law), history, teleology, and aesthetic intuition and production-are the metaphysical domains left to the philosopher after the ‘correction’ of the three Kantian Critiques.

22 Schelling's writings are cited from the Historisch-kritische Ausgabe der Bayerischen Akademie der Wissenschaften, ed., H. M. Baumgartner, W. G. Jacobs, H. Krings et al (StuttgartBad Carnstatt: Frommanns, 1976 f.) [abbreviated $H k A$ ] where available, or from Friedrich Wilhelm Joseph Schelling's sämmtliche Werke, ed. K. F. A. Schelling (Stuttgart: Cotta 18561861) [abbreviated SSW].

${ }^{23}$ J. G. Fichte, “While Reading Schelling’s Transcendental Idealism,” in PRFS, pp. 11920.
${ }^{24}$ Ibid., p. 119.
${ }^{25}$ Ibid., p. 120.
${ }^{26}$ Allgemeine Deduktion des dynamischen Prozesses oder Kategorien der Physik, in Friedrick Wilhelm Joseph Schelling, Zeitschrift für speculative Physik, Bd. I, ed. Manfred Durner (Hamburg: Felix Meiner Verlag, 2001) pp. 69-70.

${ }^{27}$ Ibid., pp. 70-72.

${ }^{28}$ Ibid., pp. 162-63.

${ }^{29}$ Ibid., pp. 164-65.

${ }^{30}$ See Fichte to Schelling, 27 December 1800 and Schelling to Fichte, 15 May 1801 in PRFS, pp. $49 \& 51$.

${ }^{31}$ Further Presentations from the System of Philosophy, in PRFS, pp. 209-11.

32 Ibid., pp. 213-216. 
${ }^{33}$ Ibid., pp. 223-24. The idea of construction expounded here is essentially the same as that expounded in the Critical Journal in 1803. See SSW V: 125-140.

${ }^{34}$ Fichte to Schelling, 15 November 1800 in Fichte-Schelling Correspondence, in PRFS, p. 42 .

${ }^{35}$ Ibid., p. 45.

${ }^{36}$ Further Presentations, in PRFS, p. 221. In 1801, Hegel wrote: "The Absolute is the night, and the day is younger than it. ... But the task of philosophy consists in uniting these presuppositions: to posit being in non-being, as becoming; to posit dichotomy in the Absolute, as its appearance, to posit the finite in the infinite, as life.”-The Difference between Fichte’s and Schelling's System of Philosophy, tr. H. S. Harris \& Walter Cerf (Albany: SUNY Press, 1977) pp. 93-94.

${ }^{37}$ Further Presentations, in PRFS, p. 262. 